\title{
Espiritualidade e Religiosidade como práticas de enfrentamento ao uso abusivo de drogas
}

\author{
Spirituality and Religiosity as coping practices \\ in abuse use of drugs
}

\author{
Adriane Pinto Diniz' \\ Gabriel Silvestre Minucci ${ }^{2}$ \\ Rauni Jandé Roama-Alves ${ }^{3}$ (i) \\ Luís Paulo Souza e Souza ${ }^{4}$ (1)
}

\begin{abstract}
'Secretaria Municipal de Saúde, Prefeitura de Curvelo (Curvelo). Minas Gerais, Brasil. adrianepdiniz@yahoo.com.br
Universidade Federal de São João del Rei (São João del Rei). Minas Gerais, Brasil. gabrielsilcci@gmail.com 3Universidade Federal de Rondonópolis (Rondonópolis). Mato Grosso, Brasil. rauniroama@gmail.com ${ }^{4}$ Autor para correspondência. Universidade Federal do Amazonas (Coari). Amazonas, Brasil. luis.pauloss@hotmail.com
\end{abstract}

\begin{abstract}
RESUMO | Objetivou-se conhecer a relação entre a espiritualidade e a religiosidade com o uso abusivo de álcool e outras drogas, por meio da análise de publicações em revistas científicas. Foi realizada revisão integrativa da literatura de acordo com publicações encontradas nas bases de dados eletrônicas PePSIC, Index Psi, BDENF e LILACS. Utilizaram-se os seguintes descritores: "Espiritualidade"; "Religiosidade"; "Usuários de drogas"; "Abuso de álcool"; "Fatores de proteção". Para seleção das publicações, foram aplicados os seguintes critérios de inclusão: pertencer à faixa temporal de 2007 a 2017; estar disponível na íntegra, eletrônica e gratuitamente; estar em português; ser identificada a temática foco de análise no título e/ ou resumo e/ou na leitura integral do artigo. O único critério de exclusão adotado foi a repetição entre as bases de dados. Selecionaram-se 13 artigos. Como resultado, verificou-se efeitos protetores da espiritualidade e da religiosidade na maioria dos estudos, como: aspecto preventivo entre adolescentes; promoção de hábitos saudáveis entre gestantes; promoção de hábitos saudáveis via comunidades religiosas; prevenção de recaídas durante o processo de desintoxicação do uso abusivo de drogas lícitas e ilícitas. Porém, houve neutralidade da mediação dessas crenças e práticas em grupos de universitários e hapatopatas. Tais dados favorecem o fortalecimento da discussão científica da espiritualidade e da religiosidade, tanto em seus aspectos positivos, negativos e neutros, no cotidiano e na singularidade dos usuários, dentro da lógica da integralidade e humanização na promoção da saúde.
\end{abstract}

PALAVRAS-CHAVE: Usuários de drogas. Abuso de álcool. Espiritualidade. Religiosidade. Fatores de proteção.

\begin{abstract}
The objective of this study was to know the relationship between spirituality and religiosity with the abuse of alcohol and other drugs, through the analysis of publications in scientific journals. An integrative literature review was performed according to publications found in the electronic databases PePSIC, Index Psi, BDENF and LILACS. The following descriptors were used: "Spirituality"; "Religiosity"; "Drug users"; "Alcohol abuse"; "Protection Factors". For the selection of publications, the following inclusion criteria were applied: belong to the time range from 2007 to 2017; be available in full, electronically and for free; to be in Portuguese; be identified the thematic focus of analysis in the title and/or abstract and/ or in the full reading of the article. The only exclusion criterion adopted was the repetition between the databases. Thirteen articles were selected. As a result, there were protective effects of spirituality and religiosity in most studies, such as: preventive aspect among adolescents; promotion of healthy habits among pregnant women; promotion of healthy habits via religious communities; prevention of relapse during the detoxification process of licit and illicit drug abuse. However, there was neutrality in the mediation of these beliefs and practices in groups of university students and hapatopaths. These data favor the strengthening of the scientific discussion of spirituality and religiosity, both in its positive, negative and neutral aspects, in the daily life and uniqueness of users, within the logic of comprehensiveness and humanization in health promotion.
\end{abstract}

KEYWORDS: Drug users. Alcohol abuse. Spirituality. Religion. Protective factors. 


\section{Introdução}

A prática do consumo de substâncias psicoativas está presente em diferentes épocas da história da humanidade e permeia de diversas formas os contextos sociais, políticos, econômicos e religiosos. Entre as drogas usadas, estão incluídas as substâncias lícitas, como o álcool, o tabaco, alguns medicamentos, e as substâncias ilícitas, como a maconha, o crack, a dietilamida do ácido lisérgico (LSD), a metilenodioximetanfetamina (mais conhecida como ecstasy), os opiáceos, entre outras.

No contexto mundial, o consumo per capita de álcool puro foi em média 21,2 litros para os homens e 8,9 litros para as mulheres em 2010. A cada ano são contabilizadas, aproximadamente, 3,3 milhões de morte no mundo como resultado do consumo abusivo do álcool (Organização Mundial da Saúde, 2014). Sobre o consumo de drogas ilícitas, estimou-se que em 2014, um em cada 20 adultos consumia pelo menos uma substância, totalizando prevalência mundial de 5,2\%. Dentre as mais utilizadas, destacam-se a maconha, os estimulantes, os opióides e a heroína (United Nations Office On Drugs And Crime (UNODC), 2016).

Já no Brasil, segundo dados da Pesquisa Nacional de Saúde em 2013, a prevalência do consumo abusivo de álcool na população adulta (18 anos ou mais) foi de $13,7 \%$, sendo maior entre os homens e entre adultos jovens (18-29 anos de idade; 30-39 anos de idade) (Garcia \& Freitas, 2015). Em relação ao uso de tabaco, a mesma pesquisa apontou que a prevalência foi de $15 \%$, estimando que cerca de 21,8 milhões de pessoas consumiam algum produto do tabaco, sendo que a maioria fazia uso de tabaco fumado. Maiores prevalências foram encontradas entre os homens e entre adultos com 40 a 59 anos de idade (Malta et al., 2015). $\mathrm{Na}$ análise do uso de substâncias ilícitas, segundo dados do II Levantamento Nacional de Álcool e Drogas, em 2012, a prevalência de consumo nos 12 meses que antecederam a pesquisa foi de 15,5 em adultos, sendo os tranquilizantes $(6,0 \%)$, a maconha $(2,5 \%)$, a cocaína $(1,7 \%)$, os estimulantes $(1,1 \%)$ e o crack $(0,7 \%)$ as substâncias mais utilizadas (Instituto Nacional de Ciência e Tecnologia para Políticas Públicas de Álcool e Outras Drogas - INPAD, 2014).

Essas substâncias provocam alterações físicas e psicológicas nas pessoas que as consomem, variando o risco em função das circunstâncias e do padrão de uso. Este padrão de alterações pode ser baixo ou altamente disfuncional, acarretando problemas de saúde e psicológicos, prejuízos nas relações sociais e familiares, além de problemas legais e com a justiça (Zeitoune et al., 2012).

Diante deste cenário, os usuários de álcool e outras drogas precisam ser considerados em toda a sua dimensão humana, visando mudança nesses padrões de consumo. Para tanto, o Ministério da Saúde, em 2004, propôs a adoção de uma política baseada na lógica da redução de danos, considerando as diversas estratégias como complementares e não concorrentes. Assim, um caminho que possibilite o retardo do início do consumo de drogas, a redução dos danos (ou a superação do consumo) é construída junto ao usuário, respeitando a sua singularidade (Brasil, 2004).

No entanto, os usuários de álcool e outras drogas apresentam baixo nível de adesão ao tratamento ou às práticas preventivas e de promoção à saúde. Isso pode estar relacionado à dificuldade dos profissionais em estabelecerem vínculos com os usuários e seus familiares, ao proporcionarem práticas que não favorecem a inserção social e familiar, além de não considerarem em sua totalidade as características e necessidades do sujeito. $O$ fenômeno do uso abusivo de álcool e outras drogas deve ser assistido na Saúde com um diálogo entre os saberes das diversas áreas afins, tendo a participação do usuário como protagonista (Manfrê, 2015; Rosa et al., 2016).

Tal diálogo favoreceria o acesso mais amplo aos fatores de risco e proteção que possam estar presentes na vida do usuário. Dentre os fatores de risco, destacam-se: consumir tabaco e álcool em idade precoce; apresentar pares que usam drogas ou álcool; apresentar pares que aprovam ou valorizam seu uso; apresentar pares que adotam postura de rejeição sistemática às regras, práticas ou atividades organizadas; rede social desfavorável (Andrade \& Ramos, 2011; Wandekoken et al., 2011; Rozin \& Zagonel, 2012; Brasil, 2014; Hung et al., 2015; Hovdestad et al., 2015). Já os fatores de proteção envolvem atividades recreativas, escolares, profissionais, religiosas ou outras que não envolvam o uso indevido de álcool e outras drogas (Andrade \& Ramos, 2011; Rozin \& Zagonel, 2012; Brasil, 2014; Witkiewitz et al., 2016; Zerbetto et al., 2017).

Neste estudo, buscou-se compreender especificamente o papel das práticas religiosas e espirituais nesse processo. Witkiewitz et al. (2016) reforçam 
que a importância da religiosidade e das práticas espirituais na etiologia e manutenção do consumo de álcool e outras drogas tem sido citada na literatura há mais de 70 anos, sendo ambíguos os efeitos destas práticas no enfrentamento e tratamento. Ora os estudos descrevem os benefícios potenciais, ora discutem que a atividade religiosa não é inteiramente protetora contra o abuso do álcool e outras drogas.

Essas controversas devem estimular que novas pesquisas na área sejam realizadas, a fim de esclarecer se eficazmente a espiritualidade e a religiosidade, comumente associadas à transformação pessoal, podem auxiliar na transformação pessoal de comportamentos de uso de substâncias. A transformação pessoal pode envolver elementos tais como a atenção plena e a aceitação de um problema, que formam as bases de tratamentos comportamentais para distúrbios de uso de substâncias, incluindo o álcool e outras drogas (Witkiewitz et al., 2016; Witkiewitz et al., 2014; Dawson et al., 2012). Alguns autores têm demonstrado ainda que a espiritualidade e a religiosidade, quando presentes na vida dos adultos e adolescentes, são fatores influenciadores das relações sociais e familiares em preceitos éticos, políticos e culturais, incentivando a adoção de hábitos e condutas saudáveis, proporcionando saúde física e mental (Santos et al., 2015; Zerbett et al. 2017; Murakami \& Campos, 2012; Henning-Geronasso \& Moré, 2015).

A partir deste enfoque e tendo o conceito amplo de saúde, reconhecendo o ser humano como um ser integral, compreendido com múltiplas dimensões, faz-se necessário transpor as barreiras da atenção pontual e assistencialista à saúde, reconhecendo, além da habitação, meio ambiente, família, aspectos biológicos e psicossociais, renda e lazer, a religião e a espiritualidade na mesma expressividade (Backes et al., 2012).

É importante reforçar que, neste estudo, entendese "religiosidade" como crença e prática ritualística de uma religião, tanto na participação de alguma instituição religiosa quanto no ato de rezar ou orar (Koening, 2012). A "religião" pode ser definida como uma organização de crenças e rituais relacionados com o sagrado, envolvendo regras sobre condutas orientadoras da vida num grupo social, de forma individual em comunidade (Zerbetto et al., 2017). A "espiritualidade" envolve uma relação pessoal com algo transcendente, metafísico (Deus(es) ou Poder(es) Superior(es)), em que a pessoa busca significados fundamentais da vida, podendo ou não envolver a religião (Hufford, 2010).

Diante do exposto, este artigo propõe conhecer a relação entre a espiritualidade e a religiosidade com o uso abusivo de álcool e outras drogas, por meio da análise de publicações em revistas científicas. Ressalta-se aqui que foram consideradas tanto pesquisas que abordaram a espiritualidade como a religiosidade de forma conjunta ou separadamente, bem como a análise de cada uma delas desse mesmo modo, a depender de como foram suas conceituações e interações adotadas pelos autores.

Busca-se com este estudo proporcionar informações para serem utilizadas na implementação de ações preventivas, promotoras e de intervenção no cuidado de usuários. Além disso, é válido destacar que aqui o foco é avaliar as práticas religiosas e espirituais indicadas nas publicações, abstendo-se de posicionarmos a favor ou contra entidades religiosas, comunidades terapêuticas ou demais instituições.

\section{Método}

Este estudo se classifica como uma revisão integrativa da literatura, a qual foi elaborada seguindo protocolos já estabelecidos e cientificamente aceitos (Mendes et al., 2008; Souza et al., 2010).

A busca bibliográfica ocorreu em maio de 2017 e foi conduzida por dois pesquisadores, separadamente, para que houvesse rigor e validação dos resultados encontrados. Foram investigadas as bases de dados Portal de Periódicos Eletrônicos de Psicologia (PePSIC), Index Psi Periódicos Técnico-Científicos (Index Psi), Base de Dados da Enfermagem (BDENF) e a Literatura Latino-Americana e do Caribe em Ciências da Saúde (LILACS), e o acesso a estas bases foi por meio da Biblioteca Virtual em Saúde (BVS). Foram utilizados os seguintes descritores nas buscas dos artigos: "Espiritualidade"; "Religiosidade"; "Usuários de drogas"; "Abuso de álcool"; "Fatores de proteção". Além disso, foi utilizado o "AND" entres os descritores como operador booleano.

Foram encontrados, no total, 116 artigos, porém, nem todos foram analisados nesse estudo. Isto porque foram adotados, inicialmente os seguintes critérios de inclusão: ter sido publicado entre os anos de 2007 a 
2017; estar disponível na íntegra eletronicamente; possuir acesso gratuito; estar publicado em português; ter investigado o tema em questão de acordo com leitura exploratória do título e do resumo. A partir de tais critérios, incluíram-se 47 artigos. Em seguida, como critério de exclusão adotou-se a repetição entre as bases de dados, e foram excluídos 26. Restaram 21 artigos que foram submetidos a mais um critério de inclusão: a partir de uma leitura seletiva de todo seu texto, verificar novamente se seus objetivos e delineamentos estavam compatíveis com a temática foco da pesquisa. Tal procedimento objetiva analisar criticamente o texto e determinar se de fato a matéria interessa ao estudo (Porto \& Reis 2013). Desse modo, o número final de artigos incluídos foi, então, de 13. O esquema representativo dos procedimentos de seleção dos artigos é demonstrado na Figura 1.

Figura 1. Esquema representativo dos procedimentos de seleção dos artigos

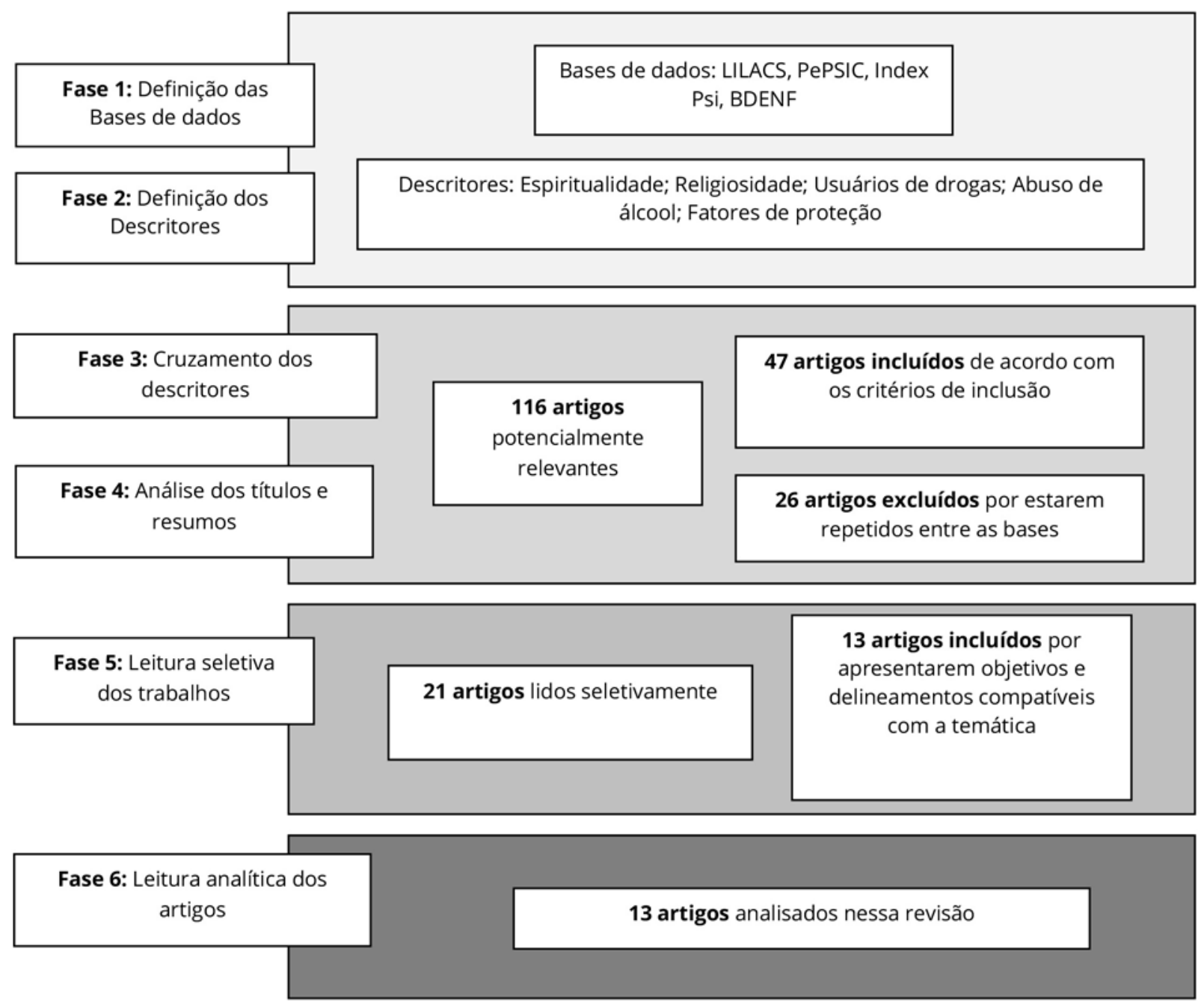

As frequências de artigos encontrados em cada base de dados, bem como as frequências após aplicação dos critérios de inclusão e exclusão podem ser vistas no Quadro 1. Dos 13 artigos encontrados, sete (54\%) foram da LILACS; um (7,5\%) da PePSIC; um (7,5\%) da Index Psi; e quatro (31\%) da BDENF (Quadro 1). 
Quadro 1. Artigos encontrados e selecionados segundo base de dados, descritores, critério de inclusão e leitura seletiva

\begin{tabular}{|c|c|c|c|c|c|}
\hline Base & Descritores & $\begin{array}{c}\text { Encontrados } \\
\text { - cruzamento } \\
\text { dos } \\
\text { descritores }\end{array}$ & $\begin{array}{l}\text { Selecionados } \\
\text { após } \\
\text { critérios de } \\
\text { inclusão }\end{array}$ & $\begin{array}{c}\text { Excluídos } \\
\text { devido } \\
\text { repetição } \\
\text { nas bases }\end{array}$ & $\begin{array}{c}\text { Selecionados } \\
\text { após leitura } \\
\text { seletiva }\end{array}$ \\
\hline \multirow{6}{*}{$\begin{array}{c}\text { Literatura } \\
\text { Latino- } \\
\text { Americana e do } \\
\text { Caribe em } \\
\text { Ciências da } \\
\text { Saúde (LILACS) }\end{array}$} & Usuários de drogas AND espiritualidade & 05 & 04 & 02 & 02 \\
\hline & Usuários de drogas AND religiosidade & 07 & 02 & 01 & 00 \\
\hline & Usuários de drogas AND fatores de proteção & 17 & 07 & 00 & 01 \\
\hline & Abuso de álcool AND espiritualidade & 05 & 03 & 01 & 01 \\
\hline & Abuso de álcool AND religiosidade & 09 & 01 & 00 & 01 \\
\hline & Abuso de álcool AND fatores de proteção & 29 & 05 & 04 & 02 \\
\hline \multirow{6}{*}{$\begin{array}{l}\text { Portal de } \\
\text { Periódicos } \\
\text { Eletrônicos de } \\
\text { Psicologia } \\
\text { (PePSIC) }\end{array}$} & Usuários de drogas AND espiritualidade & 01 & 01 & 01 & 00 \\
\hline & Usuários de drogas AND religiosidade & 01 & 01 & 01 & 00 \\
\hline & Usuários de drogas AND fatores de proteção & 02 & 02 & 01 & 01 \\
\hline & Abuso de álcool AND espiritualidade & 00 & 00 & 00 & 00 \\
\hline & Abuso de álcool AND religiosidade & 01 & 01 & 00 & 00 \\
\hline & Abuso de álcool AND fatores de proteção & 01 & 01 & 01 & 00 \\
\hline \multirow{6}{*}{$\begin{array}{l}\text { Index Psi } \\
\text { Periódicos } \\
\text { Técnico- } \\
\text { Científicos }\end{array}$} & Usuários de drogas AND espiritualidade & 01 & 01 & 01 & 01 \\
\hline & Usuários de drogas AND religiosidade & 02 & 01 & 01 & 00 \\
\hline & Usuários de drogas AND fatores de proteção & 01 & 00 & 00 & 00 \\
\hline & Abuso de álcool AND espiritualidade & 02 & 01 & 01 & 00 \\
\hline & Abuso de álcool AND religiosidade & 03 & 01 & 01 & 00 \\
\hline & Abuso de álcool AND fatores de proteção & 02 & 01 & 01 & 00 \\
\hline \multirow{6}{*}{$\begin{array}{c}\text { Base de Dados } \\
\text { da } \\
\text { Enfermagem } \\
\text { (BDENF) }\end{array}$} & Usuários de drogas AND espiritualidade & 04 & 04 & 03 & 00 \\
\hline & Usuários de drogas AND religiosidade & 01 & 01 & 01 & 00 \\
\hline & Usuários de drogas AND fatores de proteção & 08 & 03 & 01 & 01 \\
\hline & Abuso de álcool AND espiritualidade & 03 & 02 & 02 & 01 \\
\hline & Abuso de álcool AND religiosidade & 02 & 01 & 00 & 00 \\
\hline & Abuso de álcool AND fatores de proteção & 09 & 03 & 02 & 02 \\
\hline Total & & 116 & 47 & 26 & 13 \\
\hline
\end{tabular}

Por fim, realizou-se análise das 13 referências remanescentes embasada em protocolos já conhecidos (Mendes et al., 2008). Buscou-se ordenar as informações contidas nas fontes com a leitura analítica e conferir um significado global dos dados encontrados, tornando possível uma associação com conhecimentos previamente obtidos com a leitura interpretativa. Assim, seguiu-se com a caracterização de cada artigo, apresentação do conteúdo e dos conceitos importantes na área, comparação e discussão das ideias e resultados encontrados pelos autores. O tamanho amostral também permitiu analisar e discutir os resultados encontrados em cada produção, de modo a associá-los e elencar características semelhantes ou discrepantes entre os achados, bem como avaliar suas possíveis qualidades e fragilidades metodológicas.

\section{Resultados e Discussão}

A fim de organizar alguns dados referentes aos 13 artigos encontrados, foi construído o Quadro 2, no qual podem ser observadas informações como: título do artigo; autores; ano; local; tipo de estudo; população do estudo; característica analisada pelos autores (uso de álcool, uso de drogas ou ambos); periódico de publicação; base onde estava indexado. Os artigos estão apresentados neste quadro por sequência de ano de publicação, do mais antigo ao mais recente. 


\begin{tabular}{|c|c|c|c|c|c|c|c|}
\hline 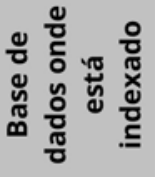 & $\stackrel{\circlearrowright}{\Xi}$ & $\stackrel{气}{\Xi}$ & $\stackrel{\check{y}}{\Xi}$ & $\begin{array}{l}\sum_{\mathrm{u}}^{u} \\
\text { 㟧 }\end{array}$ & $\stackrel{\circlearrowright}{\Xi}$ & $\stackrel{\circlearrowright}{Ð}$ & 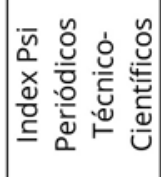 \\
\hline 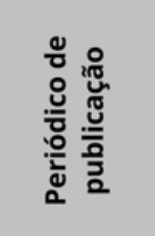 & 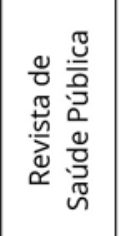 & 莺 & 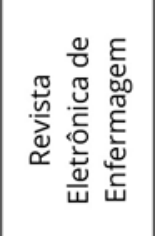 & 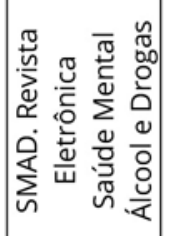 & 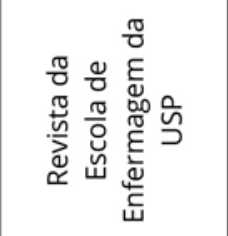 & 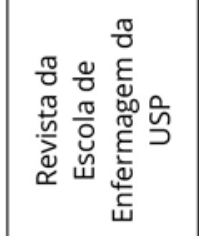 & 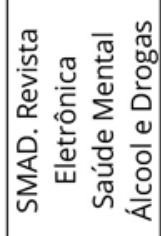 \\
\hline 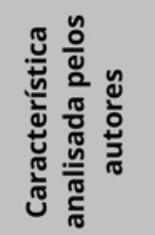 & 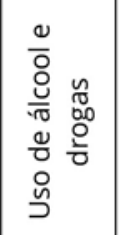 & 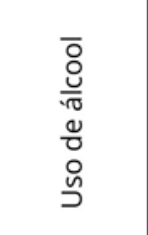 & 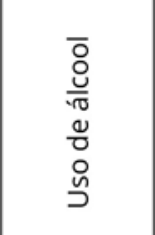 & 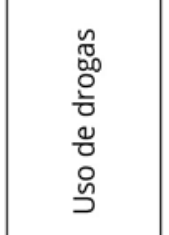 & $\begin{array}{l}\overline{0} \\
\frac{0}{n \pi} \\
\frac{\pi}{0} \\
0 \\
\stackrel{0}{1}\end{array}$ & 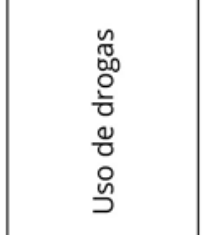 & 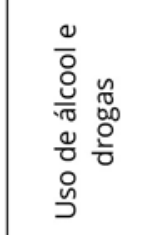 \\
\hline 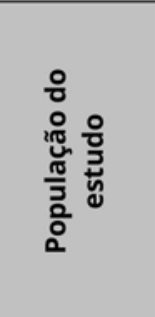 & 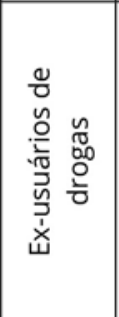 & 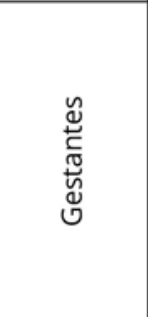 & 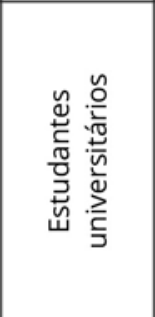 & 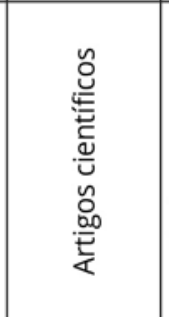 & 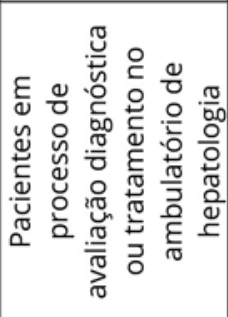 & 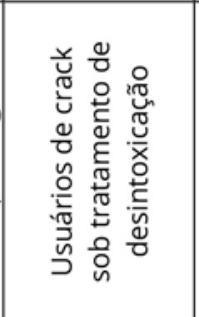 & 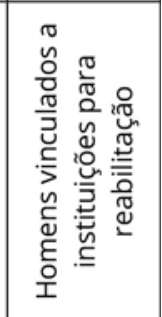 \\
\hline 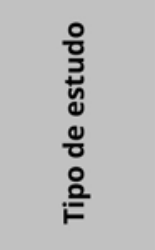 & 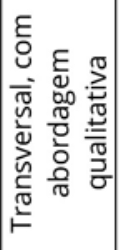 & 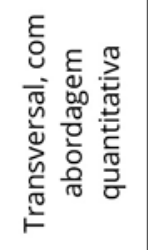 & 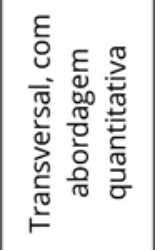 & 焉离 & 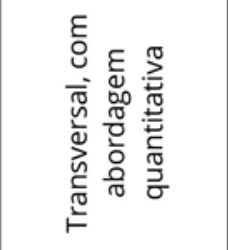 & 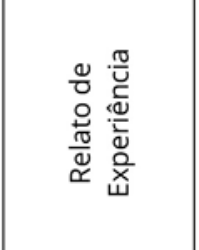 & 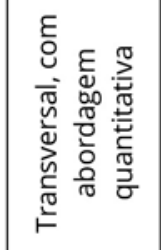 \\
\hline 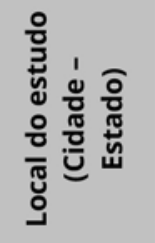 & 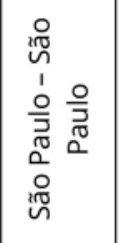 & 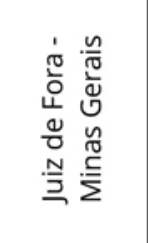 & 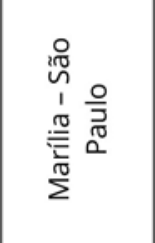 & 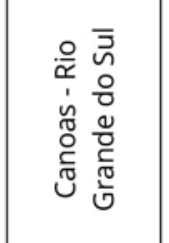 & 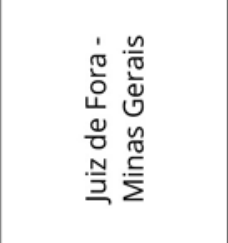 & 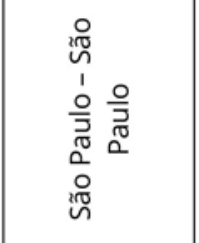 & 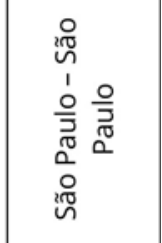 \\
\hline$\stackrel{\circ}{<}$ & ઠ̊. & 음 & $\bar{i}$ & $\bar{\sim}$ & $\stackrel{\sim}{\sim}$ & $\stackrel{\sim}{\sim}$ & $\stackrel{\nabla}{\sim}$ \\
\hline 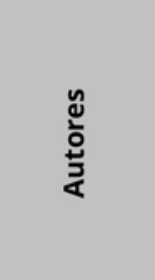 & 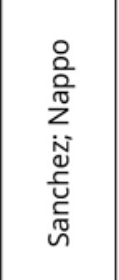 & 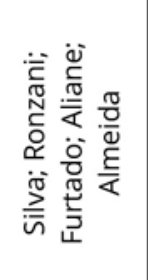 & 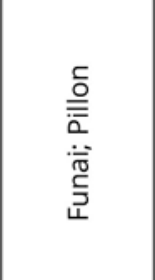 & 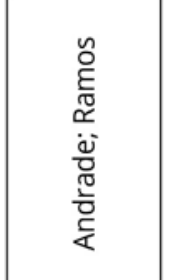 & 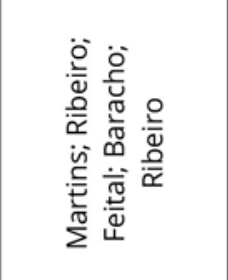 & 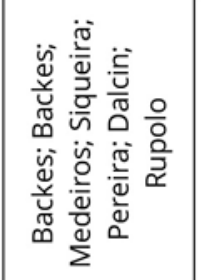 & 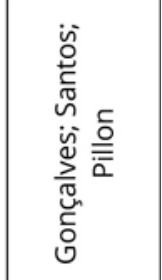 \\
\hline 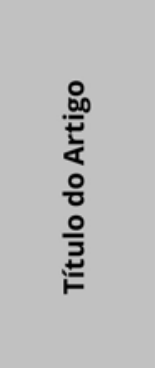 & 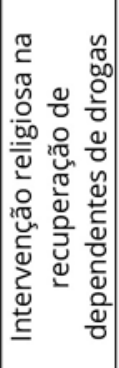 & 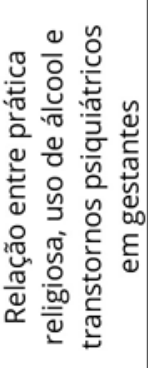 & 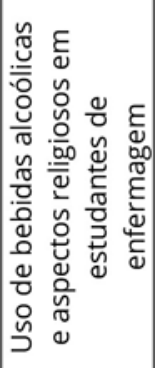 & 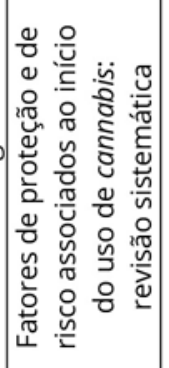 & 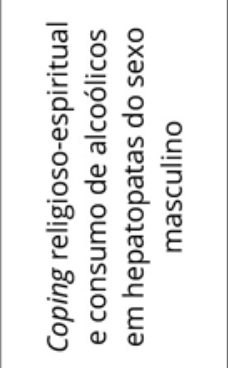 & 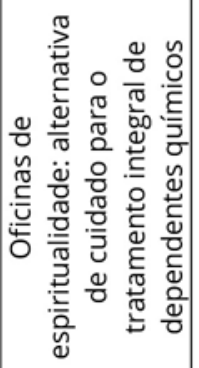 & 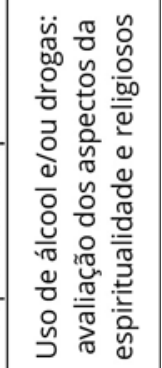 \\
\hline
\end{tabular}




\begin{tabular}{|c|c|c|c|c|c|c|}
\hline 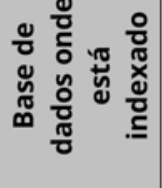 & $\stackrel{\widetilde{U}}{\Xi}$ & $\stackrel{\widetilde{U}}{\Xi}$ & 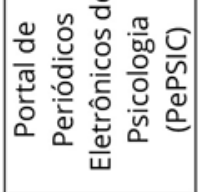 & 苂 & $\stackrel{\breve{y}}{ٍ}$ & $\begin{array}{l}\text { 岂 } \\
\text { 口̃ }\end{array}$ \\
\hline 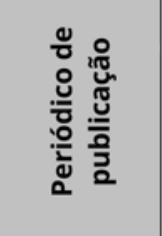 & 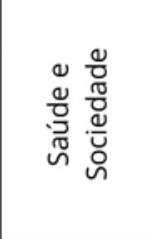 & 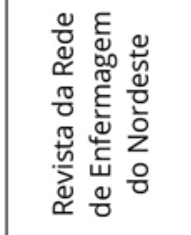 & 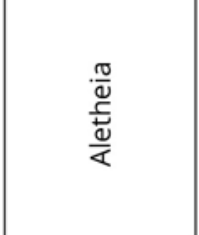 & 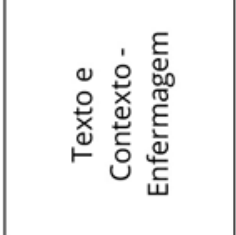 & 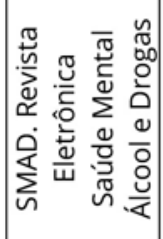 & 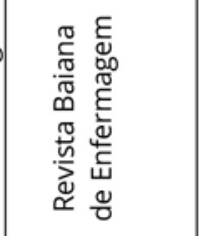 \\
\hline 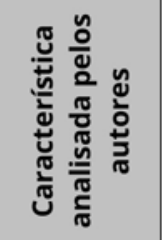 & 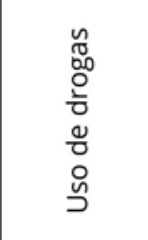 & 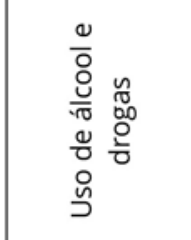 & 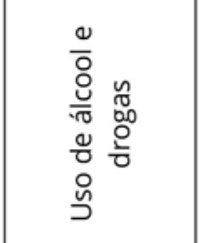 & 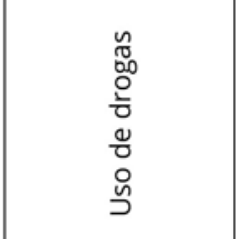 & 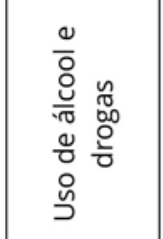 & $\begin{array}{l}\bar{o} \\
\frac{0}{\sqrt{0}} \\
\frac{0}{0} \\
0 \\
0 \\
0\end{array}$ \\
\hline 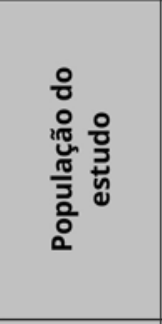 & 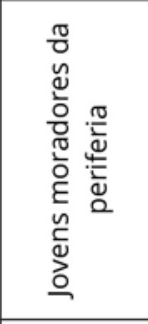 & 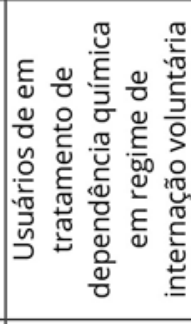 & 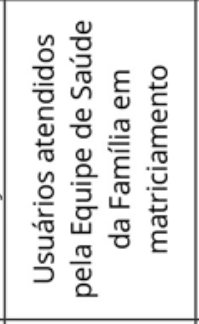 & 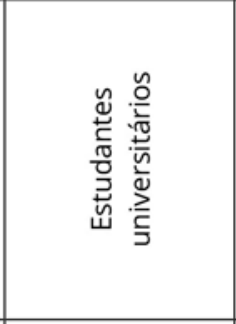 & 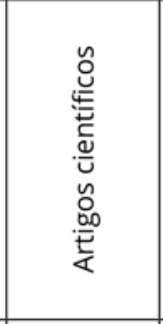 & 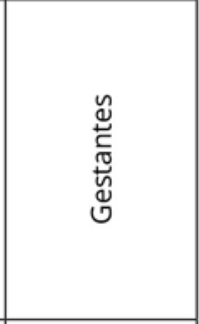 \\
\hline 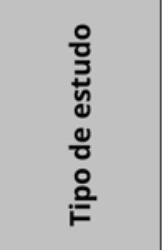 & 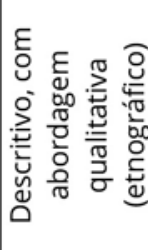 & 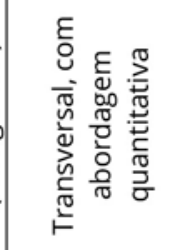 & 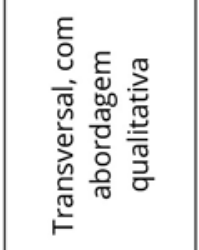 & 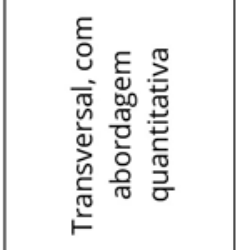 & 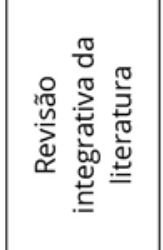 & 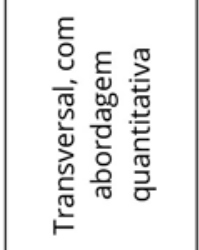 \\
\hline 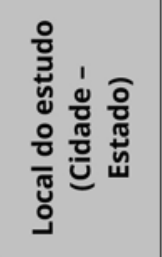 & 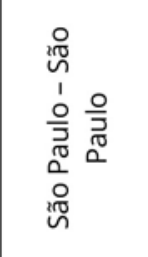 & 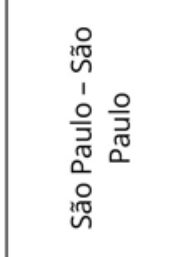 & 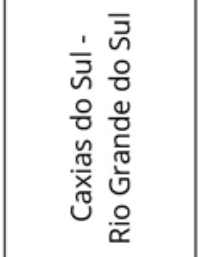 & 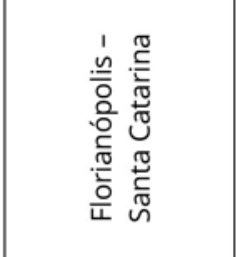 & 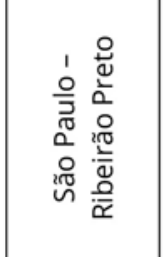 & 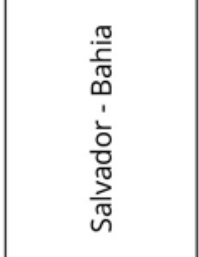 \\
\hline$\stackrel{8}{\frac{2}{4}}$ & $\stackrel{\nabla}{\sim}$ & $\frac{+}{i}$ & $\stackrel{+}{\grave{N}}$ & $\stackrel{n}{i}$ & $\stackrel{n}{\grave{N}}$ & $\frac{0}{2}$ \\
\hline 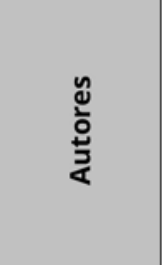 & 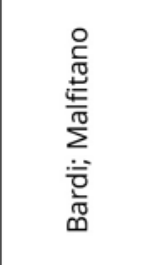 & 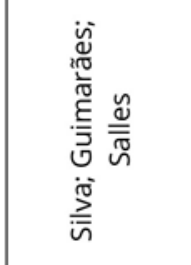 & 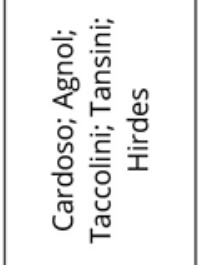 & 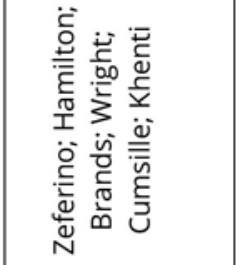 & 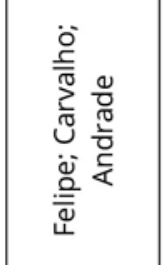 & 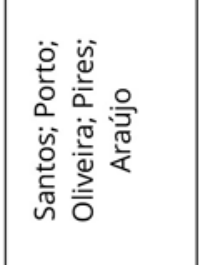 \\
\hline 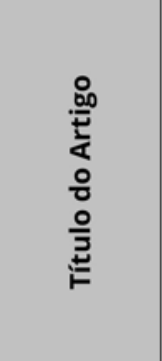 & 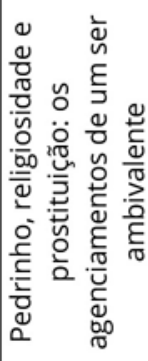 & 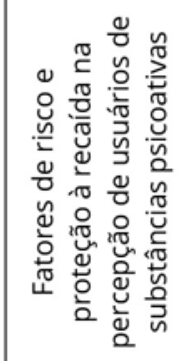 & 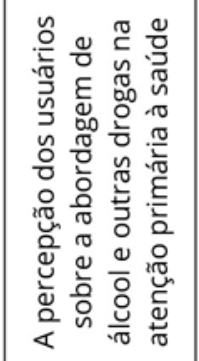 & 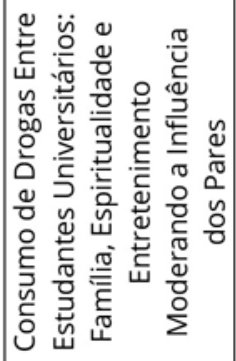 & 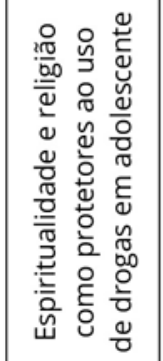 & 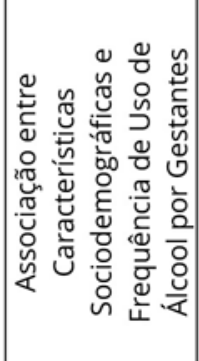 \\
\hline
\end{tabular}


Constatou-se que o ano de 2014 apresentou maior frequência de publicações $(n=4 ; 31 \%)$, seguido pelos anos de 2011, 2012 e 2015, todos com duas publicações (15\%). Em relação à característica analisada pelos autores, cinco (38\%) avaliaram aspectos da espiritualidade e da religiosidade naqueles que faziam uso de álcool e outras drogas juntos; quatro (31\%) em somente usuários de álcool; e quatro em usuários de drogas (31\%). Nas duas variáveis citadas (ano e características), foi verificada, de certa forma, determinada distribuição equilibrada entre as subvariáveis analisadas.

Em relação ao tipo de estudo conduzido, maior parte $(n=7 ; 54 \%)$ foi do tipo transversal com abordagem quantitativa, como visto em estudo semelhante anterior (Felipe, Carvalho \& Andrade, 2015). O periódico que mais frequentemente publicou sobre a temática foi o “SMAD - Revista Eletrônica Saúde Mental Álcool e Drogas", que é vinculada à Universidade de São Paulo (USP), com três artigos (23\%). Quanto à região de realização, observou-se que a maior parte das pesquisas foi realizada na região Sudeste $(n=9 ; 69 \%)$; seguido pela região Sul do Brasil $(n=3 ; 23 \%)$ e Nordeste ( $n$ $=1 ; 7,5 \%)$. Tais dados refletem o perfil de produção nacional, ainda dominada pela região Sudeste (Cirani, Campanario \& Silva, 2015).

Em relação à população de cada estudo, destaca-se que parte considerável dos artigos foi de revisão da literatura ( $n=2 ; 15 \%)$ e avaliou grupos de gestantes $(n=2 ; 15 \%)$ e grupos de universitários $(n=2 ; 15 \%)$. No estudo de revisão realizado por Andrade e Ramos (2011), buscou-se verificar quais seriam os fatores associados ao início do uso de canabis em adolescentes, de acordo com publicações entre os anos de 1999 a 2008. No outro estudo de revisão, realizado por Felipe et al. (2015), as autoras buscaram identificar as evidências disponíveis na literatura sobre a importância da espiritualidade/religião como protetores ao uso de drogas na mesma população. Foi delimitado o tempo de 2003 a 2013. Dentre os principais resultados encontrados, verificou que: a prática da religião teria associação inversa com o uso precoce tanto de maconha como de tabaco; jovens sem prática religiosa apresentaram duas ou três vezes mais chances de usar maconha quando comparados aos jovens que possuíam práticas católicas; o fator protetivo esteve presente independentemente do tipo de religião; os filiados às outras religiões, quando comparados aos católicos, tiveram menor probabilidade de se envolver com drogas; foi observado, também, que a religiosidade e a espiritualidade favoreceram níveis elevados de bem-estar, autoeficiência, autorrespeito ao corpo e à mente.

Pôde-se observar que ambos os artigos de revisão demonstraram, de forma geral, que a espiritualidade e a religiosidade se apresentaram como fatores protetivos ao uso de drogas, pois possivelmente proporcionaram efeitos cognitivos moduladores da quantidade de consumo e de autocontrole, que favorecem recurso pessoais conservadores em relação a tal uso. Nesse quesito, é relevante serem destacadas as redes sociais de convivência dos jovens, que de acordo com os conflitos vivenciados nessa época podem influenciar atitudes frente as drogas. Esses resultados são compatíveis com investigação realizada por Wills, Simons, Sussman e Knight (2016). Porém, ressalta-se que os dados podem não ser generalizáveis a outras drogas e populações, já que especificamente foram investigadas a maconha, tabaco e grupo de adolescentes.

Em relação ao grupo de gestante, destacam-se as publicações de Silva et al. (2010) e Santos et al. (2016). Especificamente no primeiro estudo, foi verificada relação entre prática religiosa, prevalência de diagnósticos psiquiátricos e consumo alcoólico em 260 gestantes de Juiz de Fora, Minas Gerais. Por sua vez, a pesquisa realizada por Santos et al. (2016) verificou a associação entre características sociodemográficas e a frequência de uso de álcool em 268 gestantes atendidas em uma maternidade pública de Salvador, Bahia. Os principais resultados encontrados demonstraram associação entre a frequência de uso de álcool e a religião, demonstrando que quanto mais frequentes eram as práticas religiosas, menor foi o uso de álcool ou outras substâncias psicoativas. Ou seja, mais uma vez a religião foi identificada como elemento influenciador da frequência de uso de álcool, podendo atuar como um fator de proteção.

Sendo assim, a prática da religiosidade se mostrou como influenciadora na adoção de condutas referentes à abstinência ou à diminuição do uso de álcool e outras drogas em gestantes. A religiosidade mostrou mediar o enfrentamento de situações adversas ou ruins, no fortalecimento pessoal, além de proporcionar uma ressignificação da gestação, com ênfase no cuidado nessa fase (Silva et al., 2010; Santos et al., 2016). Esses resultados são compatíveis com achado internacional relatado por Jesse e Reed (2004). As autoras verificaram que em mulheres das regiões montanhosas da América do Norte os altos níveis de espiritualidade e de religiosidade foram 
significativamente correlacionados com maior satisfação de apoio social, níveis mais altos de autoestima e diminuição dos níveis de tabagismo. As variáveis sociodemográficas, psicossociais e espirituais explicaram 25\% da variação na frequência do tabagismo.

Teoricamente, Jesse, Schoneboom e Blanchard (2007) defendem que esses resultados seriam esperados, de acordo com a Holistic Obstetrical Problem Evaluation theory (teoria Holística de Avaliação de Problemas Obstétricos; HOPE). Ela pressupõe que a espiritualidade e a religiosidade proporcionam um sentimento de presença da existência de algo maior e melhor para além do "ser humano". A teoria considera os domínios biopsicossociais e descreve os valores que uma muIher grávida atribui ao sentir-se perto de um deus ou de um poder superior na oração. Tais valores favoreceriam habilidades de conversar com familiares e amigos sobre assuntos espirituais, ler materiais relacionados com o espírito, praticar oração ou meditação, acreditar no perdão, buscar significado na vida e valorizar a religião e o espiritual. Uma outra suposição interessante da teoria é de que quando parteiras, enfermeiras e profissionais de saúde veem a gravidez de forma holística, reconhecem com mais precisão riscos perinatais.

Além disso, é válido ressaltar que as duas pesquisas citadas apresentam limitações, de acordo com os relatos dos próprios autores. Na conduzida por Santos et al. (2016), o fato da amostra ser intencional pode ter influenciado os achados. Além disso, pode ter ocorrido uma subestimação do relato de consumo de álcool pelas gestantes, levando em consideração que o uso de álcool não é socialmente bem aceito, principalmente em um grupo específico como o de gestantes. Já no estudo de Silva et al. (2010), a limitação se refere à definição de "praticante" ou "não praticante" de alguma religião, que se deu apenas por uma simples pergunta, não apresentando uma avaliação mais consistente sobre o conceito de "religiosidade".

Outros dois artigos realizaram investigações da relação da espiritualidade e religiosidade em grupos de estudantes universitários, obtendo resultados diferentes dos encontrados em adolescente e gestantes. Não foi encontrada significativa relação entre espiritualidade e religiosidade com consumo de álcool e outras drogas (Zeferino et al., 2015; Funai \& Pillon, 2011).

Zeferino et al. (2015), na análise de respostas de 250 estudantes de uma universidade pública em Florianópolis, Santa Catarina, investigaram o papel da família, da espiritualidade e do entretenimento como moderadores da relação da influência dos pares sobre o consumo de drogas. Os resultados indicaram que nenhuma das variáveis investigadas foram significativas como moderadoras dessa relação. Como limitação do estudo, destacou-se o fato da amostra ser não probabilística, fato que pode ter influenciado os achados.

Funai e Pillon (2011) buscaram identificar o padrão de uso de álcool e o comportamento religioso entre estudantes de enfermagem de uma instituição pública de Marília, São Paulo. A amostra intencional foi composta por mulheres e para coleta dos dados foram utilizados dois instrumentos: (a) questionário - cujo objetivo era a coleta de informações sociodemográficas e aspectos religiosos; (b) Teste de Identificação de Problemas Relacionados ao Uso de Álcool (AUDIT), instrumento norte-americano, traduzido e utilizado em diversos países, principalmente por sua fácil aplicação e baixo custo, sendo composto apenas por dez questões. Os resultados não evidenciaram que o comportamento religioso foi um fator de proteção. Ao contrário, mostraram que os estudantes "bebedores problemáticos" declararam pertencer, em sua maioria, à religião espírita $(35,2 \%)$, seguidos pelos católicos e os evangélicos, com prevalências semelhantes (16,5\%). Também foi evidenciado que possuir família praticante de alguma religião não foi fator significativo de proteção para o uso de bebidas alcoólicas em níveis "problemáticos" (Funai \& Pillon, 2011). Como limitação, destaca-se que o uso de amostragem intencional.

Além disso, esses resultados não corroboram estudos internacionais que tiveram objetivos e delineamentos semelhantes (Kathol \& Sgoutas-Emch, 2017; Carmack \& Lewis, 2016); Giordano et al., 2015). No estudo de Funai e Pillon (2011), teoricamente, os autores esperavam encontrar a espiritualidade e religiosidade como fatores de proteção, principalmente, em razão das habilidades cognitivas de modulação e de autocontrole que possivelmente proporcionariam, como visto nos estudos anteriormente citados sobre adolescentes e como encontrado nos internacionais. Tanto esses últimos autores, como Zeferino et al. (2015), solicitam a realização de novas investigações, como as longitudinais, a fim de verificar se esses resultados se repetem. E em caso de repetição, considera-se aqui que sejam elaboradas hipóteses teóricas especificas para a população brasileira de universitários. 
Em relação aos demais grupos populacionais estudados pelos autores amostrados nesta revisão, destaca-se o estudo de Martins et al. (2012), em que foi avaliado o uso do coping religioso/espiritual (CRE) em pacientes adultos portadores de hepatopatias na modulação do consumo alcoólico durante o período de abril a dezembro de 2009. O CRE se refere aos comportamentos e crenças religiosas apresentados pelas pessoas para facilitar a resolução de problemas e prevenir ou aliviar consequências emocionais negativas de situações estressantes (Foch, Silva, \& Enumo, 2017).

Foram utilizados os seguintes instrumentos: Questionário CAGE de rastreamento de possível Síndrome de Dependência a alcoólicos na vida; o AUDIT e a Escala de coping religioso/espiritual (Escala CRE). Foram encontrados resultados abaixo da mediana em coping religioso/espiritual negativo (CREN; estratégias negativas/prejudiciais religiosas e/ou espirituais para manejar o estresse diário) e positivo (CREP; estratégias positivas/benéficas religiosas e/ou espirituais para manejar o estresse diário) em participantes com CAGE-negativo (que indica não presença de dependência). Tais resultados evidenciaram a maior presença do coping em prováveis dependentes. Os autores verificaram que, possivelmente, a condição de saúde mais a dependência favoreceriam as estratégias de coping. A limitação principal do estudo, de acordo com os autores, foi não ter controlado o quanto a doença influenciaria também tais estratégias, o que provavelmente interferiu nos resultados da pesquisa.

Os grupos que mais foram investigados, foram aqueles que eram ou foram usuários de álcool e outras drogas ( $n=6$ ) (Bardi \& Malfitano, 2014; Cardoso et al., 2014; Gonçalves et al., 2014; Silva et al., 2014; Backes et al., 2012; Sanchez \& Nappo, 2008). Sanchez e Nappo (2008) buscaram identificar intervenções religiosas emergentes para recuperação da dependência de drogas em ex-usuários. O estudo foi realizado em São Paulo, capital, entre 2004 e 2005. Foram conduzidas 85 entrevistas com ex-usuários de drogas que haviam utilizado recursos religiosos e não-médicos para tratar a dependência e que estavam há pelo menos seis meses em abstinência. Foram analisados grupos de católicos, evangélicos e espíritas. As entrevistas foram constituídas por questões sobre aspectos sociodemográficos, religiosidade, histórico de consumo de drogas, tratamentos médicos para dependência de drogas, tratamento religioso e prevenção ao consumo de drogas pela religião. Os resultados indicaram que os evangélicos foram os que mais utilizaram a religião como forma única de tratamento, seguidos pelos católicos, com certa aversão ao papel do médico e farmacológicos em ambos os casos. Os espíritas foram os que aceitaram o tratamento misto. Os entrevistados relataram que as variáveis que mais os mantiveram em abstinência foram relativas ao suporte, à pressão positiva e ao acolhimento recebido no grupo, e à oferta de reestruturação da vida pelo apoio incondicional dos líderes religiosos.

Backes et al. (2012) trouxeram um relato de experiência relacionado ao processo de desintoxicação de usuários de crack em São Paulo, por meio de oficinas de espiritualidade. Nestas oficinas, buscou-se alcançar o cuidado na sua integralidade, tendo sido observado uma transformação gradual e contínua na vida de alguns dos usuários participantes. Assim, diante de suas experiências profissionais, os autores indagaram: "por que a espiritualidade ainda gera tanto desconforto entre os profissionais da saúde e outros, mesmo sabendo das suas evidências positivas no enfrentamento das incertezas, dores e enfermidades de toda ordem?" (Backes et al., 2012: 1255). A partir do que foi vivenciado nessas oficinas, os autores verificaram que a prática da espiritualidade se constituiu como uma estratégia essencial do tratamento, tendo em vista o poder agregador, animador e dinamizador de vida e esperança que promoveu. Conhecer sobre a religião e o modo singular de vida de cada usuário foi também uma importante ferramenta de fortalecimento dos seus mecanismos de enfrentamento, servindo como ajuda para potencializar as práticas promotoras de saúde (Backes et al., 2012).

Ao analisar mais um grupo populacional quanto ao uso de drogas, Silva et al. (2014) investigaram uma amostra de 50 usuários de substâncias psicoativas em tratamento de dependência química em regime de internação voluntária, objetivando conhecer, na percepção dos usuários, os fatores de risco e proteção à recaída. Observou-se que a religiosidade foi citada como principal rede de suporte para prevenção às recaídas, seguida dos grupos de apoio. Todavia, destaca-se que o local da pesquisa foi uma comunidade terapêutica que está ligada a fatores religiosos, o que pode ter interferido nos resultados.

Gonçalves et al., (2014), no estudo em São Paulo, avaliaram aspectos da espiritualidade e religiosidade em 138 usuários de álcool e/ou drogas do sexo masculino vinculados a instituições para reabilitação ou grupo de mútua ajuda. Utilizando um questionário 
sociodemográfico, o AUDIT versão $C$ e a versão brasileira da Spirituality Self Rating Scale, que é uma escala que visa mensurar o quanto o sujeito considera ou julga importantes questões pertinentes à sua dimensão espiritual e as aplica em sua vida. Os autores observaram que a espiritualidade identificada entre os participantes aparentou estar relacionada à busca de uma qualidade de vida. Relacionou-se a isso o fato do reconhecimento de que o sentimento pessoal possa estimular um desfecho positivo quanto ao enfrentamento do problema, facilitando a manutenção do estado de abstinência, melhorando os relacionamentos interpessoais e ajudando a tolerar sentimentos que rompam com o equilíbrio emocional, como a ansiedade (Gonçalves et al., 2014).

Bardi e Malfitano (2014) buscaram identificar as redes sociais formais e informais de jovens que diziam usar drogas ilícitas na periferia urbana de um município de médio porte de São Paulo. Para tanto, os autores apresentam a história de "Pedrinho" e os seus caminhos para a obtenção de suportes, centrados em sua mãe, em uma colega da prostituição e em dois líderes religiosos (um pastor e um pai de santo).

Durante o acompanhamento do cotidiano do "Pedrinho", foi possível compreender uma dimensão bastante presente em sua vida: a religiosidade. Para lidar com as dificuldades advindas do uso de drogas, ele participava do candomblé por acreditar mantê-lo ocupado, levando-o a "pensar menos na droga". O pai de santo (que era uma travesti) se destacava como uma importante fonte de "suporte social informal", pois ocupava o papel de amigo com quem o Pedrinho poderia contar nos momentos de dificuldades e alucinação do uso da droga. Em outros momentos, o sujeito do estudo frequentava a Igreja Evangélica, o que o levava a distanciar-se dos estigmas que o perturbavam. O jovem transitava entre as duas religiões, que lhe ofereciam benefícios de suporte, cada uma com suas especificidades, para cada acontecimento vivenciado em seu cotidiano. Tanto uma quanto a outra possuíam em comum, pelo menos, o fato de concentrarem o suporte fornecido ao jovem especialmente nas relações travadas com seus líderes religiosos e no relacionamento que ele tinha com as comunidades religiosas - e não apenas nas divindades cultuadas em cada uma delas (Bardi \& Malfitano, 2014). Assim, reforça-se a importância das redes sociais criadas nas comunidades religiosas, funcionando como ferramentas de suporte no enfrentamento do álcool e outras drogas.
Complementarmente, assim como no estudo anteriormente citado, Cardoso et al. (2014) também abordaram a importância das redes sociais presentes nas comunidades religiosas. $O$ estudo realizado com usuários de álcool e outras drogas vinculados às Unidades de Saúde da Família de Caxias do Sul, Rio Grande do Sul, mostrou a identificação e o fortalecimento dessas redes atuando como fatores de proteção. As comunidades religiosas se apresentaram como uma alternativa de manutenção do convívio social, além de fomentarem o desenvolvimento de valores. Verificou-se, também, que a espiritualidade estimulou a esperança dos usuários. A busca de práticas saudáveis e o empoderamento pessoal pela fé possibilitaram novas interações sociais e reforçaram o suporte social, além de possibilitarem ao usuário, através da crença, o fortalecimento na busca do afastamento do uso abusivo de álcool e outras drogas.

Praticamente todas as investigações com usuários e ex-usuários demonstraram o fator protetivo que a espiritualidade e religiosidade podem ter no uso abusivo do álcool e de outras drogas. De forma geral, os autores levantaram hipóteses teóricas para a explicação dessa relação principalmente voltadas para o caráter de suporte social, construção de redes de apoio, de enfrentamento, autoconhecimento, de modulação e de autocontrole, em uma perspectiva social/ cognitiva, como apontado em estudos internacionais (Kelly, 2017; Krause, Pargament, Ironson, \& Hill, 2017; Mohammadkhani, Yeganeh, \& Karimpour, 2015).

\section{Conclusão}

Constatou-se que, na maior parte dos estudos, a espiritualidade e a religiosidade se apresentaram como fatores protetivos ao uso abusivo de álcool e outras drogas. Porém, como principais limitações dessa pesquisa estão: (a) o seu recorte quanto a língua de publicação, que possibilitou a análise de estudos somente nacionais; (b) o uso da revisão integrativa. Sugere-se, por exemplo, que novas revisões investiguem dados internacionais e se utilizem de revisões sistemáticas e/ou de metanálise.

Apesar disso, foram identificados especificamente resultados relacionados positivamente da espiritualidade e religiosidade com: proteção entre os adolescentes; influência de hábitos saudáveis entre as gestantes, levando-as a diminuírem o uso de álcool ou 
buscarem a abstinência; prevenção de recaídas dos usuários em processo de desintoxicação do uso abusivo de drogas lícitas e ilícitas; incentivadores da busca de uma vida saudável ao fazerem parte da rede de apoio das comunidades religiosas que tem no acolhimento a sua principal função. Resultados mostrando neutralidade foram encontrados em grupos de universitários e em hepatopatas.

De todo modo, cabe ressaltar que a hipótese levantada e defendida nessa pesquisa é de que possivelmente as relações positivas encontradas possam ser explicadas/teorizadas pela presença do CRE, em todos os grupos investigados. Como em pesquisa realizada por Foch et al. (2017), em que os resultados dos estudos analisados indicaram que a espiritualidade/religiosidade foi uma condição facilitadora para comportamentos mais saudáveis, bem como para a recuperação da saúde e para o enfrentamento de doenças crônicas e da terminalidade da vida. Porém, as autoras não refutaram os apontamentos sobre os efeitos negativos do CRE, afirmando que se deve compreender quais são as variáveis e o mecanismo pelo qual a religiosidade/espiritualidade promove ou dificulta o processo de coping no contexto da saúde por meio de novas investigações.

Ressalta-se a importância de investimentos dessas novas pesquisas nacionais que evidenciem e aprofundem o papel da espiritualidade e da religiosidade em ações preventivas e de intervenção na área de uso abusivo álcool e outras drogas. Sugere-se que sejam cautelosas quanto: (a) às definições e reconhecimento da religiosidade e da espiritualidade; (b) às análises, considerando as influências de outras variáveis, tais como: econômicas, sociais, adoção de outras práticas terapêuticas e/ou de forma complementar, dentre outras; (c) aos delineamentos, com adoção de outros tipos de método (como os longitudinais, de coorte, caso-controle, prospectivo, retrospectivo); (d) à seleção dos sujeitos (nas diversas faixas etárias, gêneros, situações de vulnerabilidade e regiões do país), seja de forma qualitativa (em diversas situações sociais) ou quantitativa (com amostras probabilísticas); (e) à elaboração teórica de hipóteses para grupos nos quais a espiritualidade e a religiosidade não se tornam moderadoras, tais como os universitários e os hepatopatas, como visto aqui. Tais estratégias poderiam favorecer o fortalecimento da discussão científica da espiritualidade e da religiosidade no cotidiano e na singularidade dos usuários.
De forma geral, notou-se que foram poucos os estudos nacionais encontrados que abordaram a temática. Assim, pode ser considerada uma área pouco explorada e que merece uma maior atenção dos pesquisadores, principalmente em razão dos dados aqui encontrados. Torna-se essencial, dentro da lógica da integralidade e humanização, que os profissionais reconheçam novas e eficazes práticas que forneçam possíveis mecanismos de enfrentamento e ajudem a maximizar as ações de promoção da saúde. Na presente investigação, verificou-se que o acesso à práticas de espiritualidade e de religiosidade poderiam ser uma delas, caso seja da vontade do usuário.

\section{Contribuições dos autores}

Diniz, A.P. eSouza, L.P. S. participaram da concepção, delineamento, busca e análise dos dados, interpretação dos resultados, redação do artigo científico. Minucci, G. S. participou da análise dos dados, interpretação dos resultados, redação do artigo científico. RoamaAlves, R. J. participou da busca e análise dos dados, interpretação dos resultados, redação do artigo científico.

\section{Conflitos de interesses}

Nenhum conflito financeiro, legal ou político envolvendo terceiros (governo, empresas e fundações privadas, etc.) foi declarado para nenhum aspecto do trabalho submetido (incluindo, mas não se limitando a subvenções e financiamentos, participação em conselho consultivo, desenho de estudo, preparação de manuscrito, análise estatística, etc.).

\section{Referências}

Andrade, T. M. R., \& Ramos, S. P. (2011). Fatores de proteção e de risco associados ao início do uso de cannabis: revisão sistemática. SMAD, Revista Eletrônica Saúde Mental Álcool e Drogas, 7(2), 98-106. Recuperado de http://www.revistas. usp.br/smad/article/view/49579/53693

Backes, D. S., Backes, M. S., Dalcin, C. B. Medeiros, M. F., Siqueira, D. F., Pereira, S. B., ... Rupolo, I. (2012). Oficinas de espiritualidade: alternativa de cuidado para o tratamento integral de dependentes químicos. Revista da Escola de Enfermagem da USP, 46(5), 1254-1259. Recuperado de http://www.scielo.br/pdf/reeusp/v46n5/30.pdf. doi: $\underline{10.1590 / S 0080-62342012000500030}$ 
Bardi, G., \& Malfitano, A. P. S. (2014). Pedrinho, religiosidade e prostituição: os agenciamentos de um ser ambivalente. Saúde e Sociedade, 23(1),42-53. Recuperado de http://www.scielo.br/pdf/sausoc/v23n1/01041290-sausoc-23-01-00042.pdf. doi: 10.1590/S010412902014000100003

Brasil. Ministério da Saúde. Secretaria de Atenção à Saúde. Coordenação Nacional DST/Aids (2004). A política do Ministério da Saúde para a atenção integral a usuários de álcool e outras drogas. Brasília: Ministério da Saúde. Recuperado de http://bvsms.saude.gov.br/bvs/ publicacoes/politica_atencao_alcool_drogas.pdf.

Brasil. Secretaria Nacional de Políticas sobre Drogas - SENAD (2014). Fé na Prevenção: prevenção do uso de drogas por instituições religiosas e movimentos afins. Brasília: Secretaria Nacional de Políticas sobre Drogas. Recuperado de http:// www.conselhodacrianca.al.gov.br/sala-de-imprensa/ noticias/2013/outubro/curso-prevencao-do-uso-dedrogas-em-instituicoes-religiosas-e-movimentos-afins2013-201cfe-na-prevencao201d

Cardoso, M. P., Agnol, R. D., Hirdes, A., Taccolini, C., Tansini, K., \& Vieira, A. (2014), A percepção dos usuários sobre a abordagem de álcool e outras drogas na atenção primária à saúde. Aletheia, 45,72-86. Recuperado de http://pepsic. bvsalud.org/pdf/aletheia/n45/n45a06.pdf

Carmack, C. C., \& Lewis, R. K. (2016). Assessing whether religious behaviors and positive and negative affect are associated with alcohol use and abuse among a sample of college students living in the Midwest. Journal of religion and health, 55(3),1107-1119. Recuperado de https://www.ncbi. nlm.nih.gov/pubmed/26915054. doi: 10.1007/s10943-0160214-y

Chen, C. Y., Dormitzer, C. M., Bejarano, J., \& Anthony, J. C. (2004). Reliosity and the earliest stages of adolescent drug involviemnt in seven contries of Latin America. American Journal of Epidemiology, 159(12), 1180-1188. Recuperado de https://academic.oup.com/aje/article-lookup/ doi/10.1093/aje/kwh151. doi: 10.1093/aje/kwh151

Cirani, C. B. S., Campanario, M. A., \& Silva, H. H. M. (2015). A evolução do ensino da pós-graduação senso estrito no Brasil: análise exploratória e proposições para pesquisa. Avaliação-Revista da Avaliação da Educação Superior, 20(1),163-187. Recuperado de http://www.scielo.br/pdf/ aval/v20n1/1414-4077-aval-20-01-00163.pdf

Dawson, D. A., Goldstein, R. B., Ruan, W. J, \& Grant, B.F. (2012). Correlates of recovery from alcohol dependence: $A$ prospective study over a 3-year follow-up interval. Alcoholism: Clinical and Experimental Research, 36(7), 1268-1277. Recuperado de https://onlinelibrary.wiley. com/doi/abs/10.1111/j.1530-0277.2011.01729.x. doi: 10.1111/j.1530-0277.2011.01729.x
Felipe, A. O. B., Carvalho, A. M. P., \& Andrade, C. U. B. (2015). Espiritualidade e religião como protetores ao uso de drogas em adolescente. SMAD, Revista eletrônica saúde mental álcool e drogas, 11(1),49-58. Recuperado de http:// pepsic.bvsalud.org/pdf/smad/v11n1/pt_08.pdf. doi: 10.11606/issn.1806-6976.v11i1p49-58

Foch, G. F. L., Silva, A. M. B., \& Enumo, S. R. F. (2017). Coping religioso/espiritual: uma revisão sistemática de literatura (2003-2013). Arquivos Brasileiros de Psicologia, 69(2),5371. Recuperado de http://pepsic.bvsalud.org/scielo. php?script=sci_arttext\&pid=S1809-52672017000200005

Funai, A., \& Pillon, S. C. (2011). Uso de bebidas alcoólicas e aspectos religiosos em estudantes de enfermagem. Revista Eletrônica de Enfermagem, 13(1),24-29. Recuperado de https://www.researchgate.net/publication/50985138_ Uso_de_bebidas_alcoolicas_e_aspectos_religiosos_em_ estudantes_de_enfermagem. doi: 10.5216/ree.v13i1.8729

Garcia, L. P., \& Freitas, L. R. S. (2015). Consumo abusivo de álcool no Brasil: resultados da Pesquisa Nacional de Saúde 2013. Epidemiologia e Serviços de Saúde, 24(2), 227-237. Recuperado de http://www.scielo.br/scielo. php?pid=S2237-96222015000200227\&script=sci_ abstract\&tIng=pt. doi: 10.5123/S1679-49742015000200005

Giordano, A. L., Prosek, E. A., Daly, C. M., Holm, J. M., Ramsey, Z. B., Abernathy, M. R., ... Sender, K. M. (2015). Exploring the relationship between religious coping and spirituality among three types of collegiate substance abuse. Journal of Counseling \& Development, 93(1),70-79. Recuperado de https://onlinelibrary.wiley.com/doi/abs/10.1002/j.15566676.2015.00182.x. doi: 10.1002/j.1556-6676.2015.00182.x

Gonçalves, A. M. S., Santos, M. A., \& Pillon, S. C. (2014). Uso de álcool e/ou drogas: avaliação dos aspectos da espiritualidade e religiosos. SMAD, Revista Eletrônica Saúde Mental Álcool e Drogas, 10(2),61-9. Recuperado de http:// pepsic.bvsalud.org/pdf/smad/v10n2/03.pdf. doi: $10.11606 /$ issn.1806-6976.v10i2p61-69

Henning-Geronasso, M. C., \& Moré, C. L. O. O. (2015). Influência da Religiosidade/Espiritualidade no Contexto Psicoterapêutico. Psicologia: Ciência e Profissão, 35(3), 711-725. Recuperado de http://www.scielo.br/scielo. php?pid=S1414-98932015000300711\&script=sci_ abstract\&tlng=pt. doi: 10.1590/1982-3703000942014

Hovdestad, W., Shields, M., Williams, G., \& Tonmyr, L. (2015), Vulnerability within families headed by teen and young adult mothers investigated by child welfare services in Canada. Health Promotion and Chronic Disease Prevention in Canada, 35(8-9), 143-150. Recuperado de https://www.ncbi.nlm.nih.gov/pmc/ articles/PMC4911135/?tool=pubmed. doi: $10.24095 /$ hpcdp.35.8/9.06 
Hufford, D. J. (2010). Visionary spiritual experiences in an enchanted world. Anthropology and Humanism, 35(2), 142158. Recuperado de https://anthrosource.onlinelibrary. wiley.com/doi/abs/10.1111/j.1548-1409.2010.01063.x. doi: 10.1111/j.1548-1409.2010.01063.x

Hung, G. C. L., Cheng, C., Jhong, J., Tsai, S. Y., Chen, C., \& Kuo, C. J. (2015). Risk and protective factors for suicide mortality among patients with alcohol dependence. The Journal Clinical Psychiatry, 76(12),1687-1693. Recuperado de http:// www.psychiatrist.com/jcp/article/Pages/2015/v76n12/ v76n1221.aspx. doi: 10.4088/JCP.15m09825

Instituto Nacional de Ciência e Tecnologia Para Políticas Públicas de Álcool e Outras Drogas - INPAD (2014). II Levantamento Nacional de Álcool e Drogas (LENAD) - 2012. São Paulo: Instituto Nacional de Ciência e Tecnologia para Políticas Públicas de Álcool e Outras Drogas, Universidade Federal de São Paulo. Recuperado de https://inpad.org.br/wpcontent/uploads/2014/03/Lenad-II-Relat\%C3\%B3rio.pdf

Jesse, D. E., \& Reed, P. G. (2004). Effects of spirituality and psychosocial well being on health risk behaviors in Appalachian pregnant women. Journal of Obstetric, Gynecologic, \& Neonatal Nursing, 33(6), 739-747. Recuperado de https://www.ncbi.nlm.nih.gov/ pubmed/15561662. doi: $10.1177 / 0884217504270669$

Jesse, D. E., Schoneboom, C., \& Blanchard, A. (2007). The effect of faith or spirituality in pregnancy: A content analysis. Journal of Holistic Nursing, 25(3), 151-158. Recuperado de https://journals. sagepub.com/doi/10.1177/0898010106293593. doi: $\underline{10.1177 / 0898010106293593}$

Kathol, N., \& Sgoutas-Emch, S. (2017). Alcohol use in college: The relationship between religion, spirituality, and proscriptive attitudes toward alcohol. Journal of religion and health, 56(2), 437-449. Recuperado de https://www.ncbi.nlm.nih. gov/pubmed/26932553. doi: 10.1007/s10943-016-0210-2

Kelly, J. F. (2017). Is Alcoholics Anonymous religious, spiritual, neither? Findings from 25 years of mechanisms of behavior change research. Addiction, 112(6), 929936. Recuperado de https://www.ncbi.nlm.nih.gov/ pubmed/27718303. doi: $10.1111 /$ add.13590

Koening, H.G. (2012). Religion, spirituality, and health: the research and clinical implications. ISRN Psychiatry, 2012, 1-33. Recuperado de https://www.ncbi.nlm.nih.gov/ pubmed/23762764. doi: $10.5402 / 2012 / 278730$

Krause, N., Pargament, K. I., Ironson, G., \& Hill, P. (2017). Religious involvement, financial strain, and poly-drug use: Exploring the moderating role of meaning in life. Substance use \& misuse, 52(3), 286-293. Recuperado de https://www.ncbi.nlm.nih.gov/pubmed/27759484. doi: 10.1080/10826084.2016.1225096
Malta, D. C., Oliveira, T. P. Vieira, M. L., Almeida, L., \& Szwarcwald, C. L. (2015). Uso e exposição à fumaça do tabaco no Brasil: resultados da Pesquisa Nacional de Saúde 2013. Epidemiologia e Serviços de Saúde, 24(2), 239-248.

Recuperado de http://www.scielo.br/pdf/ress/v24n2/22379622-ress-24-02-00239.pdf. doi: 10.5123/S1679$\underline{49742015000200006}$

Manfrê, M. M. (2015). Redes de atenção aos usuários de álcool e outras drogas: a visão dos trabalhadores e gestores de serviços de saúde mental de um município do Estado de São Paulo. Revista de Psicologia da UNESP, 14(1), 26-37. Recuperado de http://pepsic.bvsalud.org/pdf/revpsico/ v14n1/a03.pdf

Martins, M. E., Ribeiro, L. C., Feital, T. J., Baracho, R. A., \& Ribeiro, M. S. (2012). Coping religioso-espiritual e consumo de alcoólicos em hepatopatas do sexo masculino. Revista da Escola de Enfermagem da USP, 46(6), 1340-1347. Recuperado de http://www.scielo.br/scielo.php?script=sci_ arttext\&pid=S0080-62342012000600009\&lng=en\&nrm=i so. doi: $10.1590 / 50080-62342012000600009$

Mendes, K. D. S., Silveira, R. C. C. P., \& Galvão, C. M. (2008). Revisão integrativa: método de pesquisa para a incorporação de evidências na saúde e na enfermagem. Texto \& Contexto Enfermagem, 17(4),758-764. Recuperado de http://www. scielo.br/scielo.php?script=sci_arttext $\&$ pid $=$ S010407072008000400018\&lng=en\&nrm=iso. doi: $10.1590 /$ S0104-07072008000400018

Mohammadkhani, S., Yeganeh, T., \& Karimpour, K. (2015). Role of religious orientation and self-control in prediction of drug addiction potential. Journal of Health and Care, 17(3), 248-259. Recuperado de https://www.sid.ir/en/journal/ ViewPaper. aspx?id=513104

Murakami, R., \& Campos, C. J. G. (2012). Religião e saúde mental: desafio de integrar a religiosidade ao cuidado com o paciente. Revista Brasileira de Enfermagem, 65(2), 361-367. Recuperado de http://www.scielo.br/scielo.php?script=sci_ arttext\&pid=S0034-71672012000200024. doi: 10.1590/ S0034-71672012000200024

Organização Mundial da Saúde (OMS) (2014). Global status report on alcohol and health 2014. Geneva: World Health Organization. Recuperado de http://apps.who.int/iris/ bitstream/10665/112736/1/9789240692763_eng.pdf?ua=1

Porto, P. N., \& Reis, H. F. T. (2013). Religiosidade e saúde mental: um estudo de revisão integrativa. Revista Baiana de Saúde Pública, 37(2), 375-393. Recuperado de http://rbsp. sesab.ba.gov.br/index.php/rbsp/article/view/234/0. doi: 10.22278/2318-2660.2013.v37.n2.a234 
Rosa, N. M., Antunes, F., Santana, C. J., Mazzola, J. C., Silvino, M. C. S., \& Oliveira, M. L. F. (2016). Minimum standards for safe nursing care for users of alcoholic beverages. Revista de Pesquisa: Cuidado é Fundamental Online, 8(3), 4659-4667. Recuperado de http://www.seer.unirio.br/index.php/ cuidadofundamental/article/view/4070. doi: 10.9789/21755361.rpcfo.v8.4070

Rozin, L., \& Zagonel, I. P. S. (2012). Fatores de risco para dependência de álcool em adolescentes. Acta Paulista de Enfermagem, 25(2), 314-318. Recuperado de http://www.scielo.br/scielo.php?pid=S010321002012000200025\&script=sci_abstract\&tlng=pt. doi: 10.1590/S0103-21002012000200025

Sanchez, Z. V. D. M., \& Nappo, S. A. (2008). Intervenção religiosa na recuperação de dependentes de drogas. Revista de Saúde Pública, 42(2), 265-272. Recuperado de http:// www.scielo.br/scielo.php?script=sci_arttext\&pid=S0034$89102008000200011 \&$ lng=en\&nrm=iso. doi: $10.1590 /$ S0034-89102008000200011

Santos, A. R. M., Oliveira, L. M. F. T., Farias Júnior, J. C., Silva, P. P. C., Silva, E. A. P. C., \& Freitas, C. M. S. M. (2015). Associação entre prática religiosa e comportamentos de risco à saúde em adolescentes de Pernambuco, Brasil. Revista Brasileira de Atividade Física \& Saúde, 20(3), 284-296. Recuperado de http://docs.bvsalud.org/biblioref/2016/06/279/07-santos. pdf. doi: $10.12820 /$ rbafs.v.20n3p284

Santos, M. M., Porto, P. N., Oliveira, J. F., Pires, C. G. S., \& Araújo, A. J. S. (2016). Associação entre características sociodemográficas e frequência de uso de álcool por gestantes. Revista Baiana de Enfermagem, 30(2),1-9. Recuperado de https://portalseer.ufba.br/index.php/ enfermagem/article/view/14562/pdf_40. doi: 10.18471/ rbe.v30i2.14562

Silva, C. S., Ronzani, T. M., Furtado, E. F., Aliane, P. P., \& Almeida, A. M. (2010). Relação entre prática religiosa, uso de álcool e transtornos psiquiátricos em gestantes. Archives of Clinical Psychiatry, 37(4), 152-156. Recuperado de http://www.scielo.br/scielo.php?script=sci_ arttext\&pid=S0101-60832010000400002. doi: $10.1590 /$ S0101-60832010000400002

Silva, M. L., Guimarães, C. F., \& Salles, D. B. (2015). Fatores de risco e proteção à recaída na percepção de usuários de substâncias psicoativas. Revista da Rede de Enfermagem do Nordeste, 15(6), 1001-1015. Recuperado de http:// www.redalyc.org/articulo.oa?id=324041233014. doi: 10.15253/2175-6783.2014000600014

Souza, M. T., Silva, M. D., \& Carvalho, R. (2010). Revisão integrativa: o que é e como fazer. Einstein, 8(1), 102-106. Recuperado de http://www.scielo.br/pdf/eins/v8n1/pt_1679-4508eins-8-1-0102.pdf. doi: 10.1590/s1679-45082010rw1134
United Nations Office On Drugs And Crime - UNODC. (2016). World Drug Report. New York: United Nations. Recuperado de http://www.unodc.org/doc/wdr2016/WORLD_DRUG_ REPORT_2016_web.pdf

Wandekoken, K. D., Vicente, C. R., \& Siqueira, M. M. (2011). Alcoolismo parental e fatores de risco associados. SMAD, Revista Eletrônica Saúde Mental Álcool e Drogas, 7(3), 161-167. Recuperado de http://pepsic.bvsalud. org/scielo.php?script=sci_arttext\&pid=S1806$69762011000300008 \&$ Ing=pt\&nrm=iso

Wills, T. A., Simons, J. S., Sussman, S., \& Knight, R. (2016). Emotional self-control and dysregulation: A dual-process analysis of pathways to externalizing/internalizing symptomatology and positive well-being in younger adolescents. Drug and alcohol dependence, 163, S37-S45. Recuperado de https://www.ncbi.nlm.nih.gov/ pubmed/27306730. doi: 10.1016/j.drugalcdep.2015.08.039

Witkiewitz, K., Mccallion, E., \& Kirouac, M. (2016). Religious Affiliation and Spiritual Practices: An Examination of the Role of Spirituality in Alcohol Use and Alcohol Use Disorder. Alcohol Research: Current Reviews, 38(1), 55-58. Recuperado de https://psycnet.apa.org/ record/2016-30780-007

Witkiewitz, K., Warner, K., Sully, B., Barricks, A., Stauffer, C., Thompson, B. L., ... Luoma, J. B. (2014). Randomized trial comparing mindfulness-based relapse prevention with relapse prevention for women offenders at a residential addiction treatment center. Substance Use \& Misuse, 49(5), 536-546. Recuperado de https://www.tandfonline.com/ doi/abs/10.3109/10826084.2013.856922

Zeferino, M. T., Hamilton, H., Brands, B., Whright, M. G. M., Cumsille, F., \& Khenti, A. (2015). Consumo de drogas entre estudantes universitários: família, espiritualidade e entretenimento moderando a influência dos pares. Texto \& Contexto Enfermagem, 24, 125-135. Recuperado de http://www.scielo.br/scielo.php?script=sci_ arttext\&pid=S0104-07072015000600125. doi: 10.1590/0104-07072015001150014

Zeitoune, R. C. G., Ferreira, V. S., Silveira, H. S., Domingos, A. M., \& Maia, A. C. (2012). O conhecimento de adolescentes sobre drogas lícitas e ilícitas: uma contribuição para a enfermagem comunitária. Escola Anna Nery Revista de Enfermagem, 16(1), 57-63. Recuperado de http://www. scielo.br/pdf/ean/v16n1/v16n1a08

Zerbetto, S. R., Golçalves, A. M. S., Galera, S. A. F., Acorinte, A. C., \& Giovannetti, G. (2017). Religiosidade e espiritualidade: mecanismos de influência positiva sobre a vida e tratamento do alcoolista. Escola Anna Nery, 21(1), e20170005. Recuperado de http://www.scielo.br/ scielo.php?pid=S1414-81452017000100205\&script=sci_ abstract\&tlng=pt. doi: $10.5935 / 1414-8145.20170005$ 